\title{
Chemical Constituents of Methanol Fruit Extract of Xylopia aethiopica by GC-MS and FT-IR Spectroscopy
}

\author{
Ahamefula. A. Ahuchaogu ${ }^{1 *}$, P.O. Ukaogo ${ }^{1}$, Chitua E. Igara ${ }^{2}$, A. I. Obike ${ }^{1}$ \\ ${ }^{1}$ Department of Pure and Industrial Chemistry, Abia state University, Uturu. Nigeria \\ ${ }^{2}$ Department of science Laboratory Technology, AkanuIbiam Federal Polytechnic, UwanaEbonyi State, Nigeria
}

*Corresponding Author: Ahamefula. A. Ahuchaogu, Department of Pure and Industrial Chemistry, Abia state University, Uturu. Nigeria

\begin{abstract}
Xylopia aethiopica possesses great nutritional and medicinal values in traditional medicine Almost all parts of Xylopia aethiopica are very useful medicinally, but the fruits are most commonly used for therapeutic purposes. Extracts of the fruits are used in the treatment of cough, biliousness, bronchitis, rheumatism, dysentery, malaria, uterine fibroid and amenorrhea The bioactive compounds in methanol extract of Xylopia aethiopica fruits were determined using a combination of gas chromatography -mass spectrometry (GC-MS) and Fourier Transform Infra-red Spectroscopy.The compound identification was based on the molecular structure, molecular mass and calculated fragments and their functional group. The GC-MS revealed the presence of 26 compounds among them are; Mannosamine; 1-Methyl-4-[nitromethyl]-4piperidinol; Paromomycin; N-[2-[[2-Pyridylmethyl]amino]ethyl]aziridine; $\quad N-[3-[N$-Aziridyl]propylidene]-2-[2pyridyl]ethylamine; 2-Oxatricyclo[4.3.1.0(3,8)] decane; 2-Oxaadamantane; exo-2,7,7-trimethylbicyclo[2.2.1] heptan2-ol; Isopulegol; Paromomycin; Acetic acid, (3-nitro-2-pyridyl) thio-; 5-Pyrrolidin-2-ylidenemethyl-3,4dihydropyrrol-2-one; 1-(3,6-Dimethyl-2-pyrazinyl) propanone; N,N'-Bis (Carbobenzyloxy)-lysine methyl(ester.The FT-IR analysis revealed the presence of Hydroxyl $(O-H)$ stretching at $3671.5 \mathrm{~cm}^{-1}$, Aliphatic amine $(\mathrm{N}-\mathrm{H})$ at $3322.9 \mathrm{~cm}$ ${ }^{1}$ Carbonyl $(C=O)$ at $1701.5 \mathrm{~cm}^{-1}$, Aliphatic stretching $(C-H)$ at $2937.1 \mathrm{~cm}^{-1}$ and $2830.9 \mathrm{~cm}^{-1}$.
\end{abstract}

Keywords: Herbal medicine, GC-MS, Xylopia aethiopica, ethno pharmacological and FT-IR

\section{INTRODUCTION}

Dietary spices contain a wide variety of volatile and nonvolatile chemicals obtained from parts of plants such as the fruits, berries, roots, pods, and the barks, majority of which are used in herbal medicine for the treatment of diseases [1]The World Health Organization (WHO) gave a list of about 21,000 plants used for medicinal purposes around the world (2). Plants have the ability to synthesize a wide variety of chemical compounds that possess therapeutic properties and defend against attack from predators such as insects, fungi and herbivorous animals [3, 4]. About 12,000 of such compounds, representing less than $10 \%$ of the total, have been extracted, isolated and characterized. These compounds have been found to exert their effects on the human body through mechanisms that are similar to those already established in conventional drugs revealing that herbal medicines may be as effective as the latter [3,5]. Furthermore, the plant kingdom is believed to hold many new drug templates; hence, the continued investigation into ethno-medicinal plants [6].

Herbal medicine or phytomedicine is acknowledged as the most common form of alternative medicine [7]. Long in the creation of mankind, plants have been used medicinally [8]. The World Health Organization (WHO) estimates that about $80 \%$ of the world's population relies on these unconventional plant-based medicines as their primary medical intervention especially in the developing countries of the world where medical facilities/modern medicines are largely inadequate[9]. Scientific evaluation of ethno pharmacological information from medicinal plants is necessary for the development of accessible, affordable and high safety herbal therapies [10]. One of such commonly used medicinal plants is Xylopia aethiopica (Annonaceae).Xylopia aethiopica is a slim, tall, evergreen aromatic tree which grows up to 15-30 $\mathrm{m}$ high and about 60-70 $\mathrm{cm}$ in diameter. It is native to the lowland rainforest and moist fringe forest in the savanna zones of Africa, but largely found in West, Central and Southern Africa. These trees are widely distributed in the humid forest zones especially along rivers in the drier area of the region [11]. Xylopia is a Greek word 
(_xylonpikron') for _bitter wood', while aethiopica refers to its Ethiopian origin (Ethiopia). Its common names include; African pepper, Guinea pepper, spice tree, negro pepper, West African pepper and Senegal pepper [12]. An attractive spicy flavor is obtained after Negro pepper is smoked during the drying process.

Xylopia aethiopica leaves are simple, alternate, oblong, and elliptic to ovate. Its flowers are bisexual, solitary or in 3-5 flowered fasicles or in strange, sinuous, branched spikes, or cymes, up to 5.5 by 0.4 $\mathrm{cm}$ and creamy-green. Fruits of Xylopia aethiopica look like small, twisted bean-pods which are dark brown, cylindrical, 2.5 to $5 \mathrm{~cm}$ long and 4 to $6 \mathrm{~mm}$ thick. Each pod houses about 5 to 8 kidney-shaped seeds grains of approximately $5 \mathrm{~mm}$ length [11].

Its parts are used in ethno-medicine to treat various ailments including skin infections, candid as is, dyspepsia, cough, dysentery, biliousness, bronchitis, rheumatism, malaria, uterine fibroid, amenorrhea, boil, sore, fever, respiratory ailments, lumbago and neuralgia. It is also used as a mouthwash to treat toothaches [12-13]. The powdered root is used as a dressing for sores and to rub on gums for pyorrhoea and in local treatment of cancer in Nigeria. Mixture of Xylopia aethiopica with salt servesas a cure for constipation. Its decoction is used in Gabon against rheumatism and as an emetic and the leaf-sap mixed with kola nut is given to treat epileptic fits [14]. It is taken to encourage fertility and to ease childbirth. When crushed, Xylopia aethiopica is rubbed on the forehead to treat headache and neuralgia. An extract of the seeds is also used as a vermifuge for roundworms [15]. In negro pepper fruits, the essential oil (2 to 4.5\%) has been found to contain $\beta$-pinene, 1,8-cineol, $\alpha$-terpineol, terpinene-4-ol, paradol, bisabolene and other terpenes. In other work, linalool (E)- $\beta$ ocimene, $\alpha$-farnesene, $\beta$-pinene, $\alpha$-pinene, myrtenol and $\beta$ phellandrene were found [16] Among the non-volatile constituents, tetracyclic diterpenes of the kaurane type have been identified [17]. The bark oil has abundance of pinene, trans-pinocarveol, verbenone and myrtenol. However, the leaf oil is rich in spathulenol, cryptone, beta-caryophyllene and limonene [18]. The plant is said to contain anonaceine, whichis an alkaloid resembling morphine. The fruit contains volatile aromatic oil, a fixed oil and rutin [19]. The dark brown, small and twisted bean-podslike fruits are an important item of trade and the most widely used of its various morphological parts. [12]

\subsection{Botanical Classification}

Xylopia aethiopica belongs to the following category;

Kingdom: Plantae

Order: Magnoliids

Family: Annonaceae

Genus: Xylopia

Specie: Xylopia aethiopica

\section{Materials AND Methods}

\subsection{Collection and Identification of Plant Material}

The fruits were collected from a farm land in of okobe, in Obi Ngwa Local Government of Abia State, Nigeria. The fruits were authenticated by a taxonomist Dr E.O. Emmanuel of Plant Science and Biotechnology Abia State University. Specimen was deposited at the Herbarium of Department of Plant Science and Biotechnology, Faculty of Biological Sciences, Abia State University, Uturu. Nigeria under the reference number ABXA 6926.

\subsection{Preparation of Plant Materials}

The fruits were air-dried for 15 days at room temperature $\left(25-30^{\circ} \mathrm{C}\right)$. The sample was milled using and electric blender to coarse powder and powdered sample was kept in a clean closed container pending extraction. $50 \mathrm{~g}$ of pulverized dried fruit material was mixed with $150 \mathrm{ml}$ of solvent $(95 \%$ methanol ) and kept in rotary shaker at $100 \mathrm{rpm}$ overnight and filtered with What man No.1 filter paper The extract was concentrated under reduced pressure using Digital Heidolph Rotary evaporator (4000 series) and the supernatant fruit extract was decanted after complete removal of the solvent 


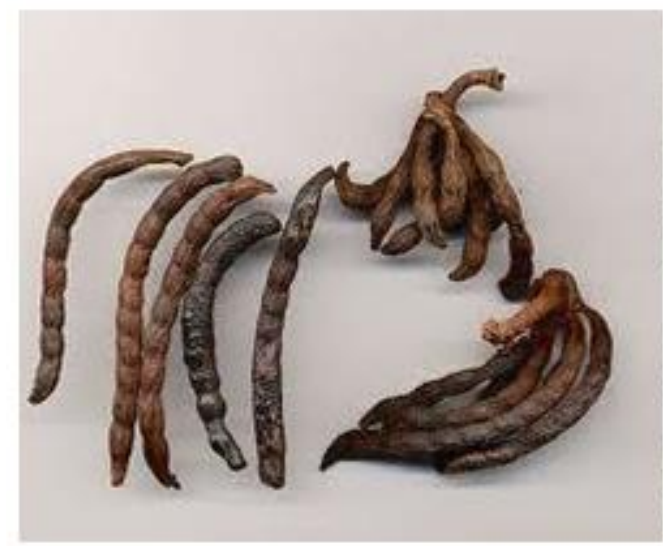

Figla. Dried fruits of Xylopia aethiopica

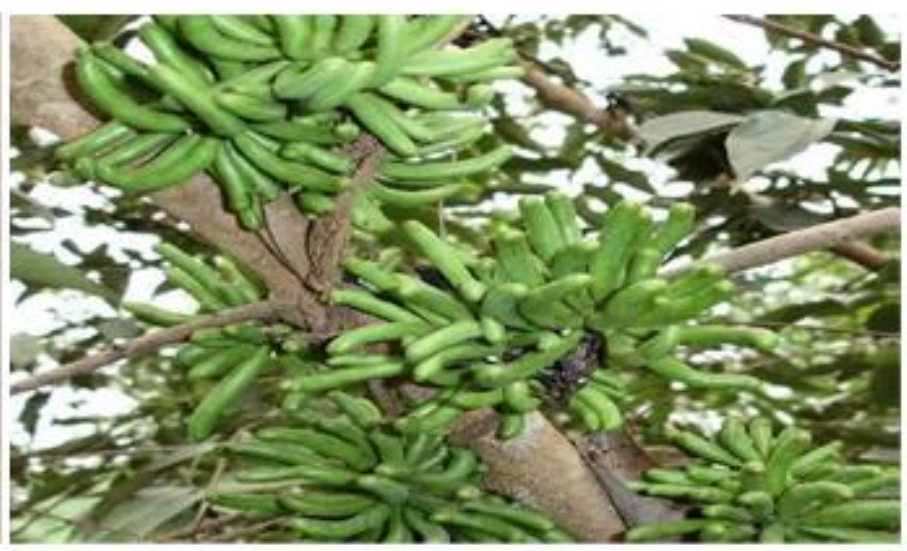

Figlb. Fresh fruits, stems and leaves Xylopia aethiopica

\subsection{GC-MS Analysis}

The GC-MS analysis of the methanol fruit extract of Xylopia aethiopica was carried out using a HP 7890 GC instrument integrated with an Agilent 5975C MSD mass spectrometer (Aligent, Santa Clara, CA, USA). The capillary column was an Agilent HP-5MS (30.m x $0.25 \mathrm{~mm}$ i.d. x $0.25 \mathrm{NM}$ film thickness), helium (Purity > $99.999 \%$ ) was used as the carrier gas, and the flow rate was $1 \mathrm{~mL} / \mathrm{min}$. The injector temperature was $250{ }^{\circ} \mathrm{C}$, and the injection mode was split less. The G.C oven temperature was held at $50{ }^{\circ} \mathrm{C}$ for $5 \mathrm{~min}$, which was increased to $210{ }^{\circ} \mathrm{C}$ at a rate of $3{ }^{\circ} \mathrm{C} / \mathrm{min}$, maintained at $210{ }^{\circ} \mathrm{C}$ for $3 \mathrm{~min}$, and finally increased to $230{ }^{\circ} \mathrm{C}$ at $150 \mathrm{C} / \mathrm{min}$. The mass spectrometer conditions were as follow: ionization energy, $70 \mathrm{Ev}$; ion Source temperature, $230{ }^{\circ} \mathrm{C}$; quadruple temperature, $150{ }^{\circ} \mathrm{C}$; quadruple mass spectrometer scan range $30-500$ atomic mass units (amu); solvent delay time 2.8 $\min$.

\subsection{Identification of Compounds}

The components of the methanol extract of Xylopia aethiopica was identified by matching the peaks with computer Wiley Ms. libraries and confirmed by comparing mass spectra of the peaks and those from literature [20].

\subsection{FTIR Spectroscopic Analysis}

FTIR analysis was performed using Perkin Elmer spectrophotometer system, which was used to detect the characteristic peaks and their functional groups using ATR (Attenuated Total Reflectance) accessory. The IR scan was performed in the wave number region of 4000-550 cm-1 (mid- infrared range).

\section{DISCUSSION}

Medicinal plants have been used for centuries for the treatment of several diseases and to promote good health [21]. People that use spices in their diets are known to have low incidence of chronic diseases [22],. One benefit of spices and herbs is that they contain bioactive components such as polyphenols that can reduce oxidative stress and modulate harmful biological pathways. Several polyphenols have been shown to have scavenging activity as well as inhibiting amylase and glucosidase activities [23]. Xylopia aethiopica commonly known as "African guinea pepper" or "Ethiopian pepper" has several medicinal properties; it is anti-tumour, anti-asthmatic, antiinflammatory and antimicrobial. It has been used for the treatment of hypotension and coronary vasodilatory conditions [24]. It has traditionally been used for the treatment of cough, dysentery, boils and sores [14]. The fruits of Xylopia aethiopica is used as a carminative, and as a post-partum tonic. Other medicinal uses are for stomach ache, treatment of bronchitis, biliousness and dysentery [25]. Mass spectrometry, coupled with chromatographic separations such as Gas chromatography (GC/MS) is normally used for direct analysis of components existing in medicinal plants and traditional medicines. In recent years GC-MS studies have been increasingly applied for theanalysis of medicinal plants as this technique has proved to be a valuable method for the analysis of nonpolar components and volatile essential oil, fatty acids, lipids and alkaloids. . FTIR is the most powerful tool for identifying the functional groups present in compounds [26]. The presented study is carried out on the 
Chemical Constituents of Methanol Fruit Extract of Xylopia aethiopica by GC-MS and FT-IR Spectroscopy

bioactive compounds present in the Xylopia aethiopica fruits by the use of GC-MS and FT-IR techniques.

The active principles with their retention time (RT), molecular formula, molecular weight (MW), concentration (peak area \%) are presented in Fig.2, which shows the presence of 26 bioactive phytochemical compounds in the methanol extract of Xylopia aethiopica. The Fourier Transform Infrared Spectroscopy was used in identification of functional groups as presented in figure 3 and table 1

Hit 2 : N,N'-Bis(Carbobenzyloxy)-lysine methyl(ester)

C23H28N2O6; MF: 630; RMF: 636; Prob 13.7\%; Lib: mainlib; ID: 59074.

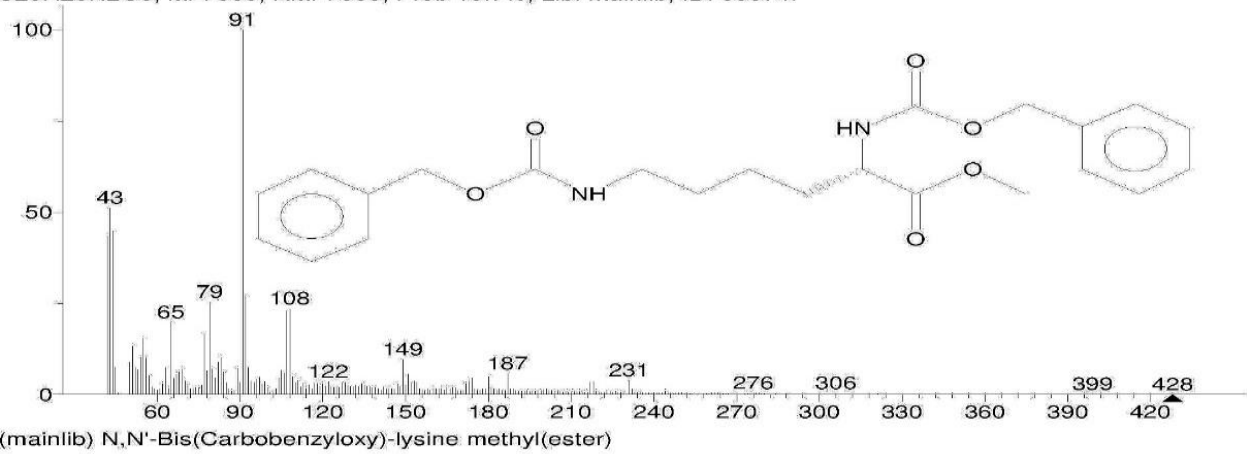

(mainlib) N,N'-Bis(Carbobenzyloxy)-lysine methyl(ester)

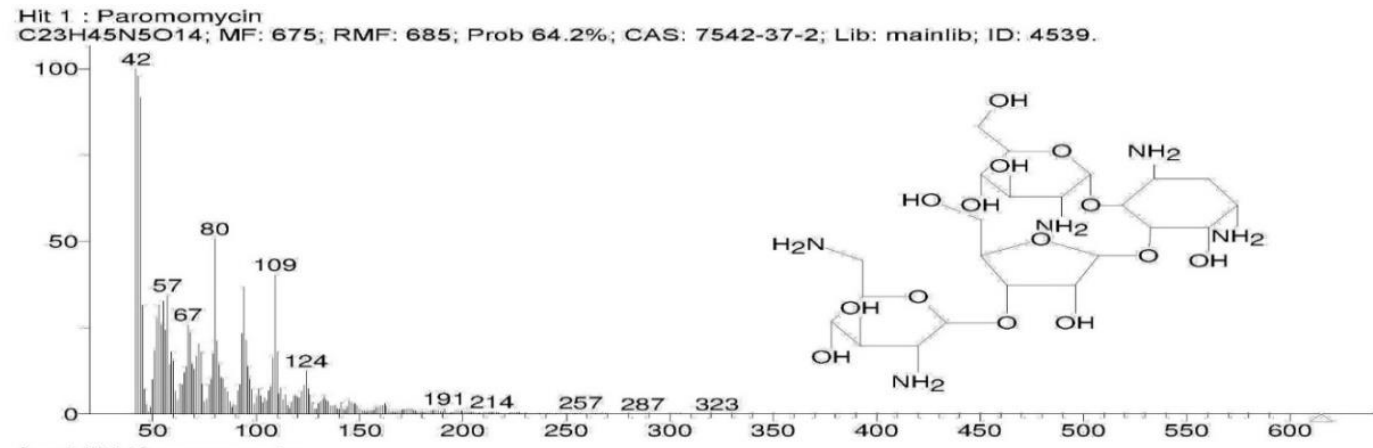

(mainlib) Paromomycin

Hit 1 : 2-Myristynoyl pantetheine

C25H44N2O5S; MF: 644; RMF: 675; Prob 17.5\%; Lib: mainlib; ID: 4545

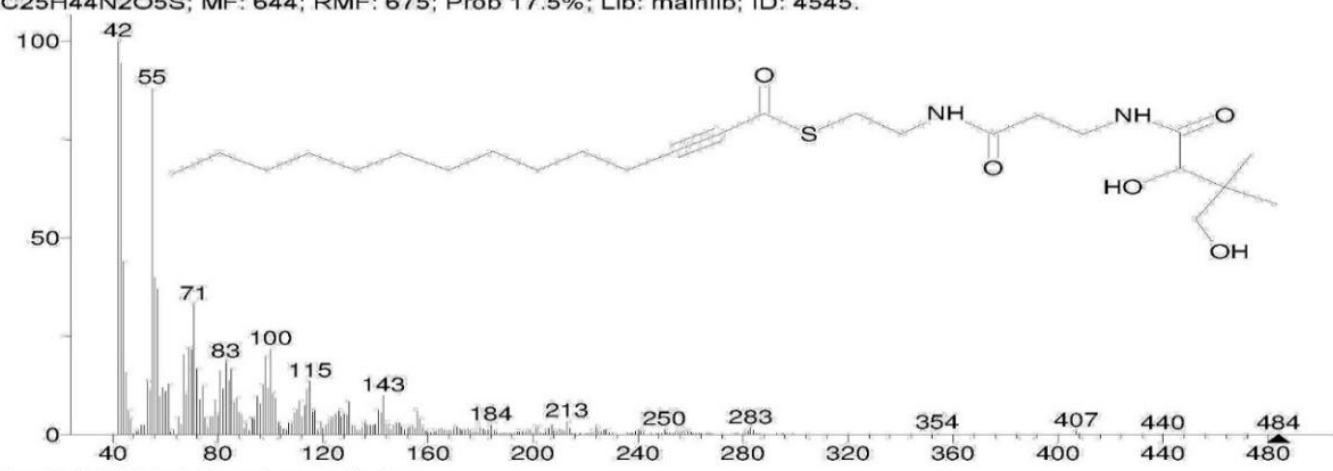

Imainlih) D-M Murictumoul nantathaino

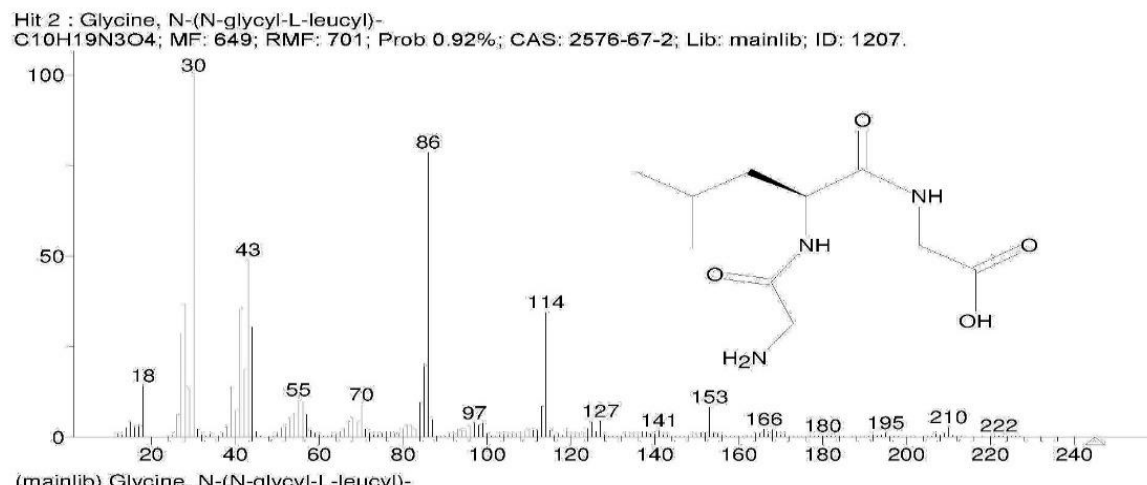

(mainlib) Glycine, $\mathrm{N}$-( $\mathrm{N}$-glycyl-L-leucyl)- 
Hit 2 N N, N-Pontamethylonobis[s-3-aminopropyl thiosulfuric acid]
C11H26N2O6S4; MF: 640; RMF: 670; Prob 14.8\%; CAS: 35871-54-6; Lib: mainlib; ID: 3142.

$100 \quad 41$

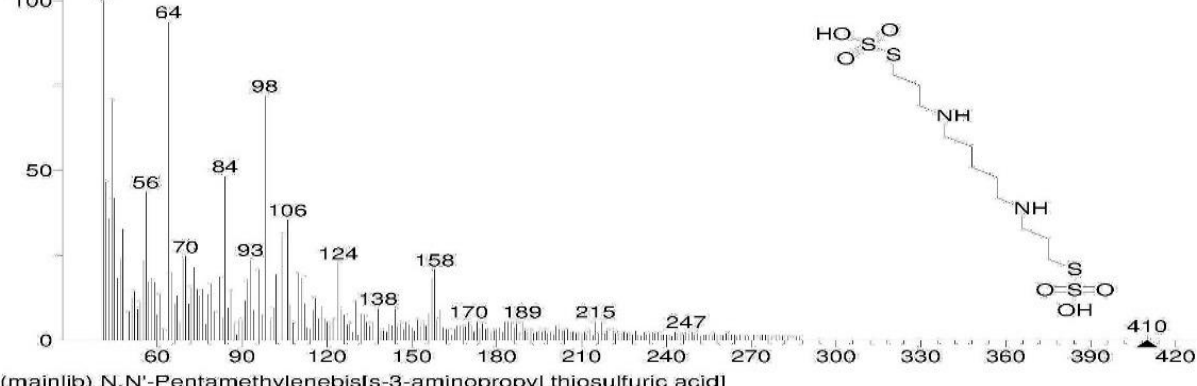

(mainlib) N.N'-PentamethvlenebisIs-3-aminopropvl thiosulfuric acidl

Hit 1 : 9-Amino-1-(4-hydroxyphenylmethyl)-3,6-diazahomoadamantane

C16H23N30; MF: 999; RMF: 999, Prob 97.5\%; CAS: 147084-70-6; Lib: mainlib; ID: 217745

$100-$

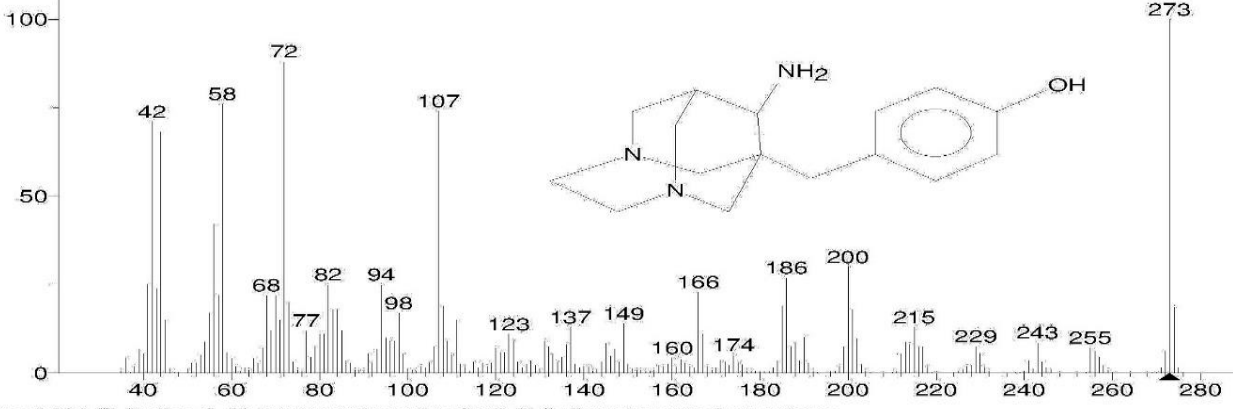

(mainlib) 9-Amino-1-(4-hydroxyphenylmethyl)-3,6-diazahomoadamantane

Hit 1 ; 2,6-Bis[2-[2-S-thiosulfuroethylaminolethoxy]pyrazine
C12H22N408S4; MF: 999; RMF: 999; Prob 98.5\%; Lib: mainlib; ID: 30894

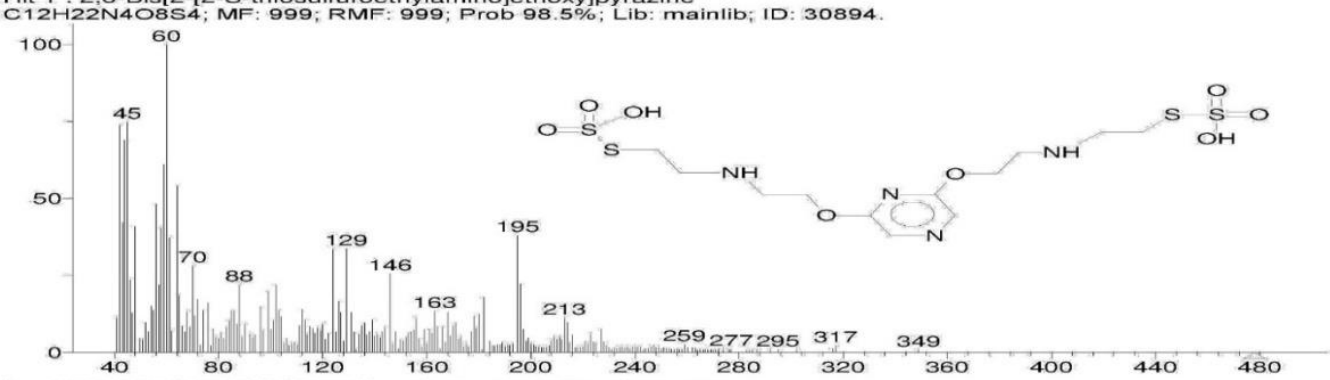

(mainlib) 2,6-Bis[2-[2-S-thiosulfuroethylamino]ethoxy]pyrazine

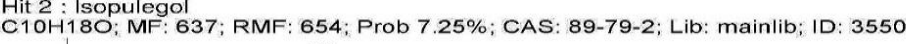

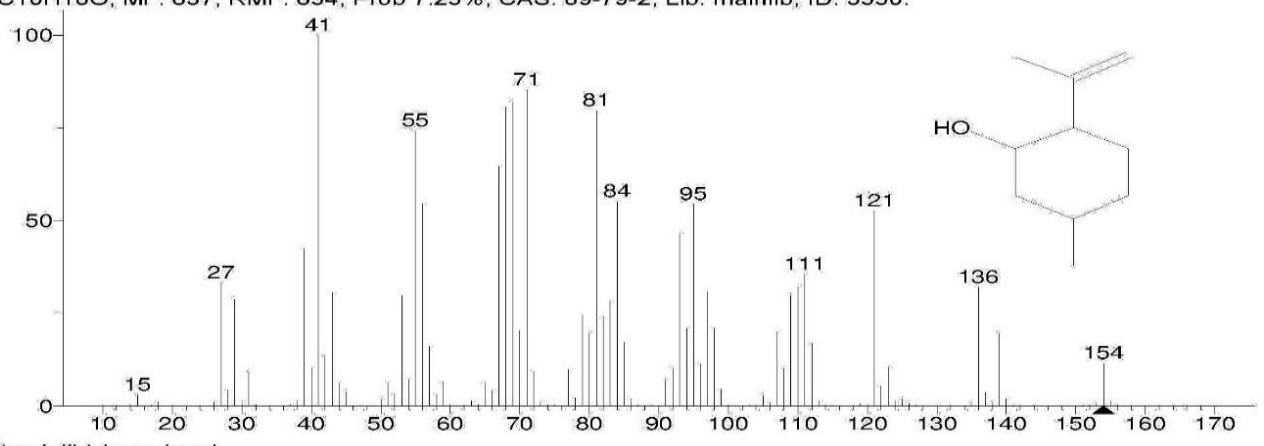

(mainlib) Isopulego

Hit 2 : N,N'-Bis (Carbobenzyloxy)-lysine methyl(ester)
C23H28N2O6; MF: 630; RMF: 636; Prob 13.7\%; Lib:

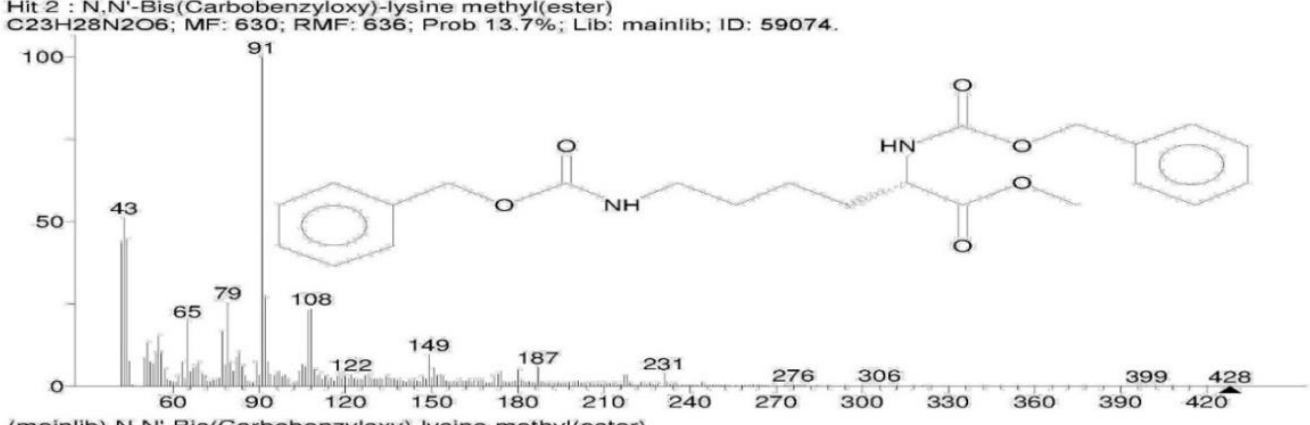

(mainlib) N,N'-Bis(Carbobenzyloxy)-lysine methyl(ester) 

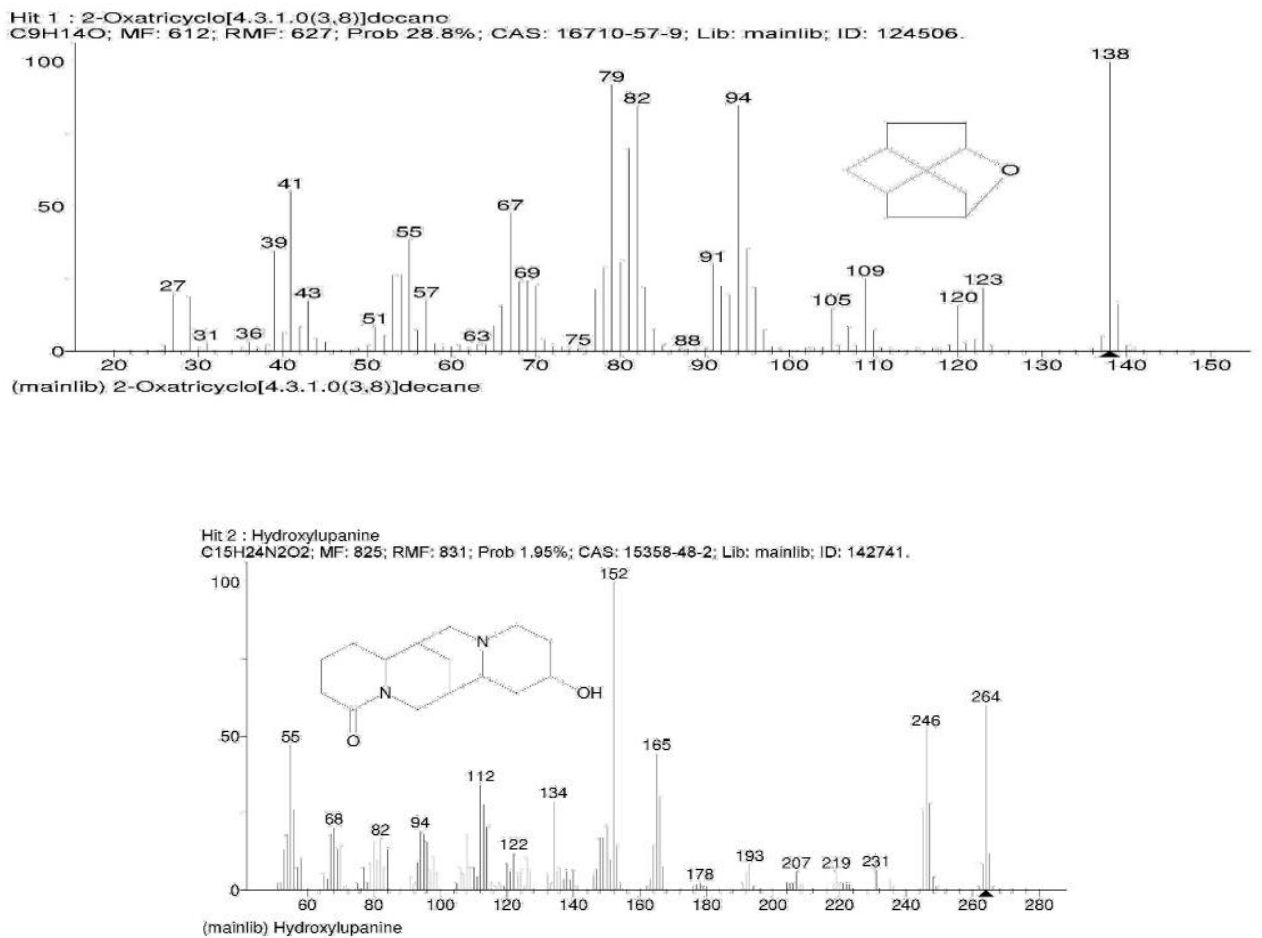

Hit 2 : 2,3-Dimethoxy-5-methyl-6-dekaisoprenyl-chinon
C59H90O4; MF: 713; RMF: 722; Prob 0.98\%; CAS: 60684-33-5; Lib: mainlib; ID: 35443.

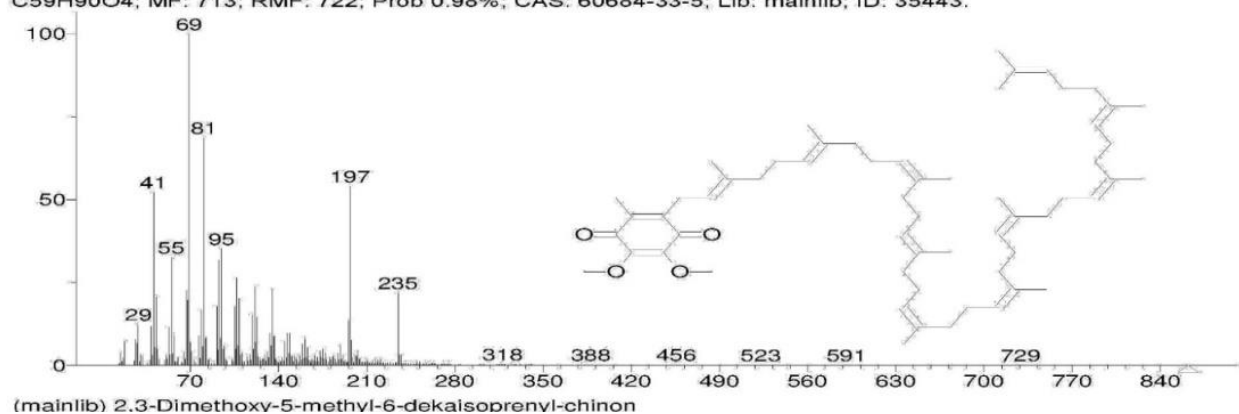
(mainlib) 2.3-Dimethoxv-5-methvl-6-dekaisoprenvl-chinon

Hit I; Tetrahydroargentamin
C.15Hi24N2O2; MF: 999; RMF: 999; Prob; 97.5\%; CAS: 27773-60-0; Lib: mainlib; ID: 142740.

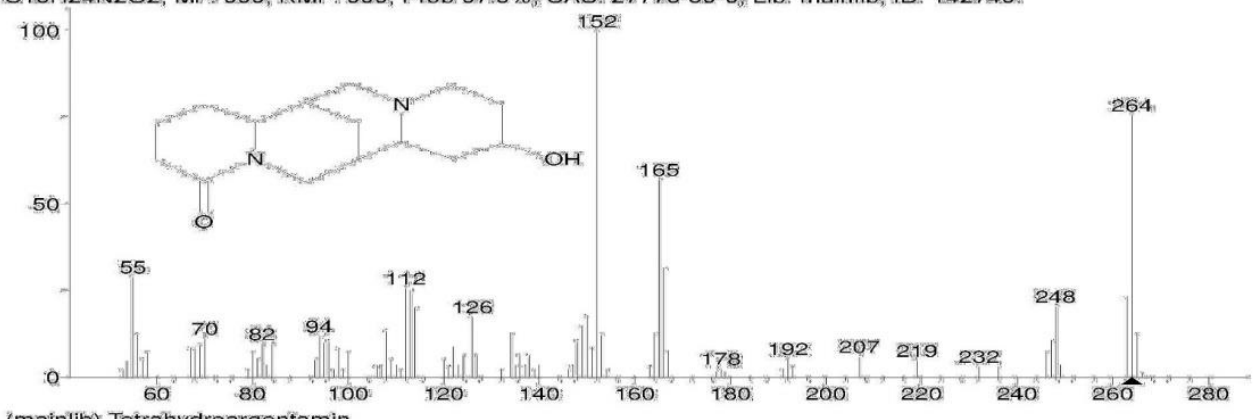

(mainlib) Tetrahydroargentamin

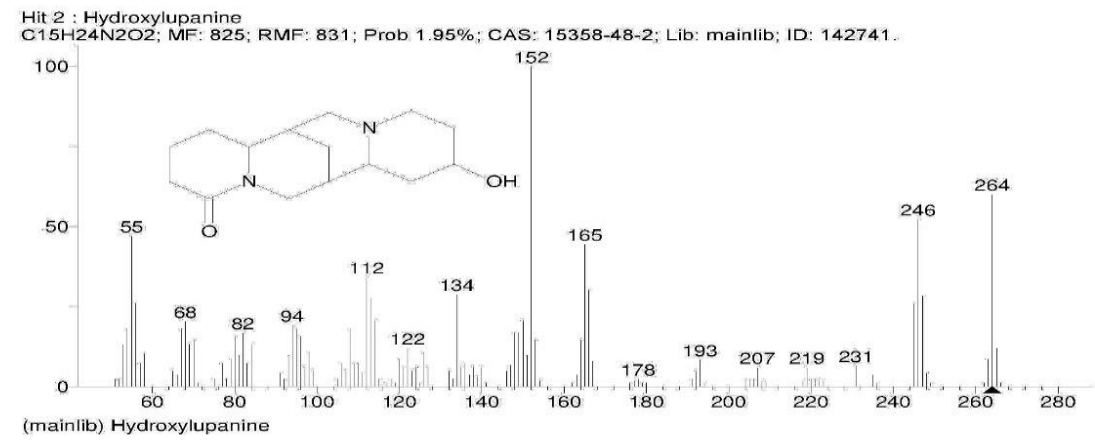




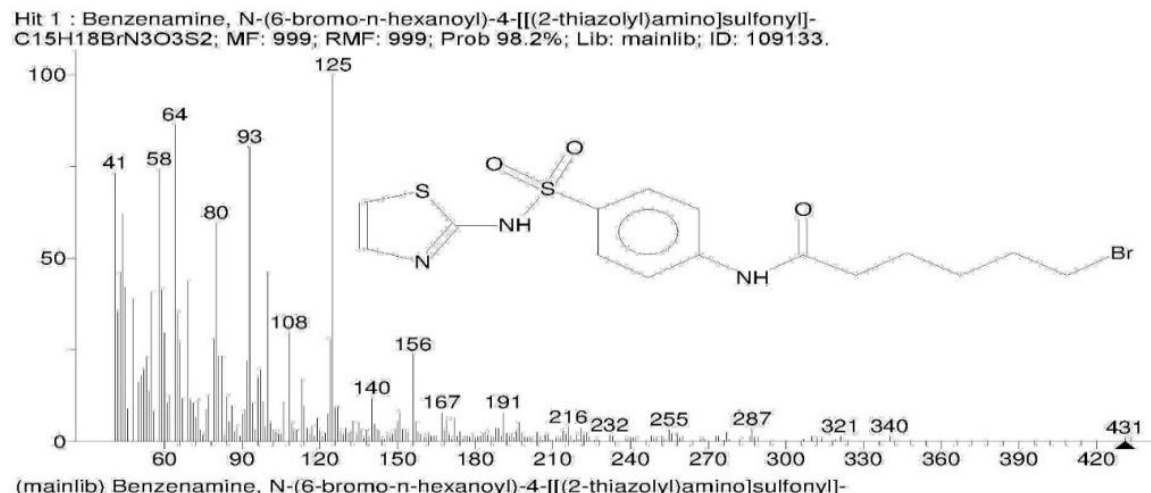

(mainlib) Benzenamine, N-(6-bromo-n-hexanoyl)-4-[I(2-thiazolyl)amino]sulfonyl]-

Hit 1 : Chlorozotocin
C9H16CIN307; MF: 999

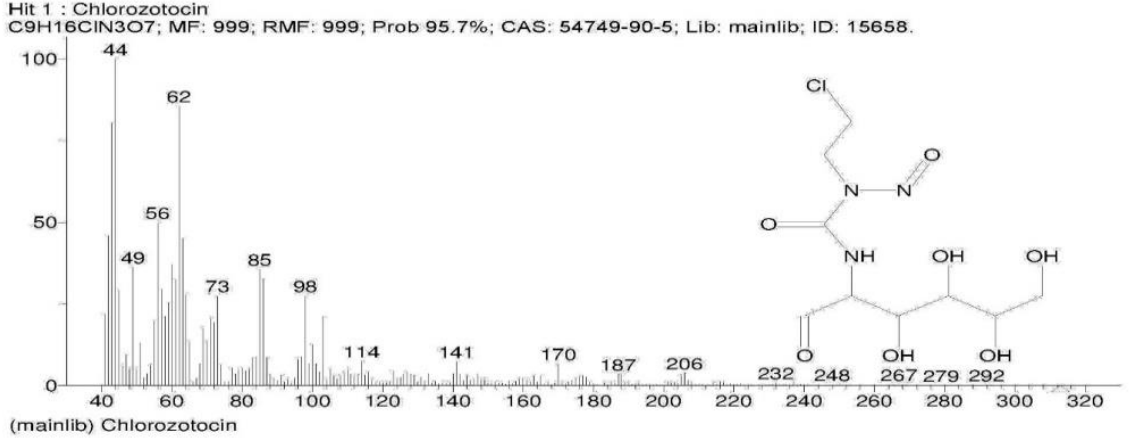

(mainlib) Chlorozotocin

Hit 1 : 5-Pyrrolidin-2-ylidenemethyl-3,4-dihydropyrrol-2-one
C9H12N2O; MF: 602; RMF: 688; Prob 9.41\%; Lib: mainlib; ID: 153308

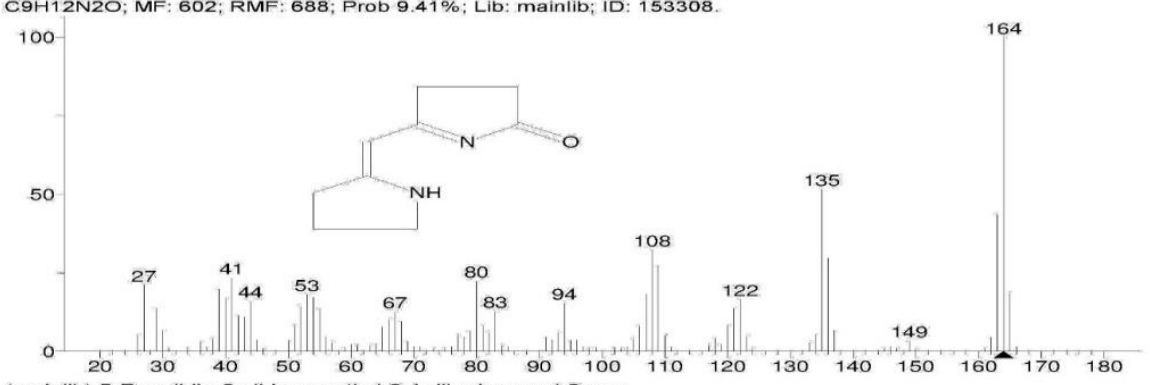
(mainlib) 5-Pyrrolidin-2-ylidenemethyl-3,4-dihydropyrrol-2-one

Hit 2 : 1-(3,6-Dimethyl-2-pyrazinyl)propanone
C9H12N2O; MF: 602; RMF: 644; Prob 9.41\%; CAS: 115609-79-5; Lib: mainlib; ID: 83356.

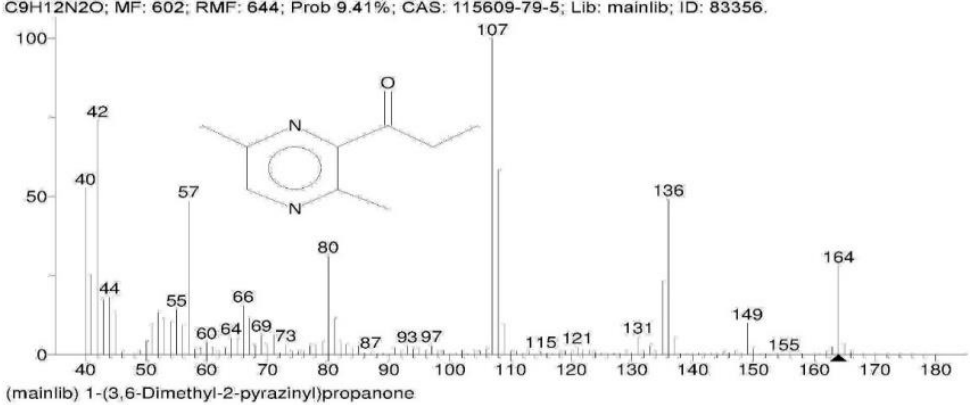

(mainlib) 1-(3,6-Dimethyl-2-pyrazinyl)propanone

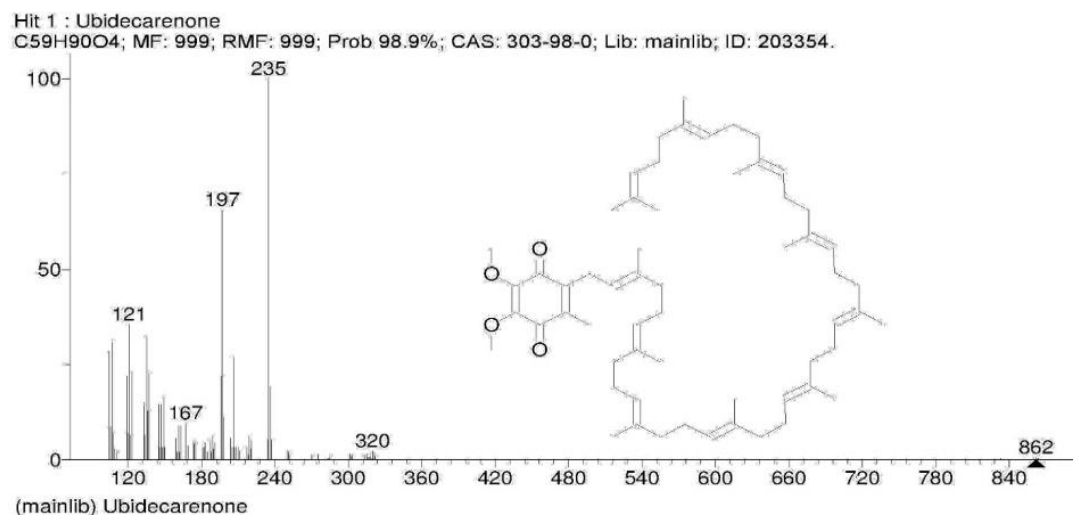




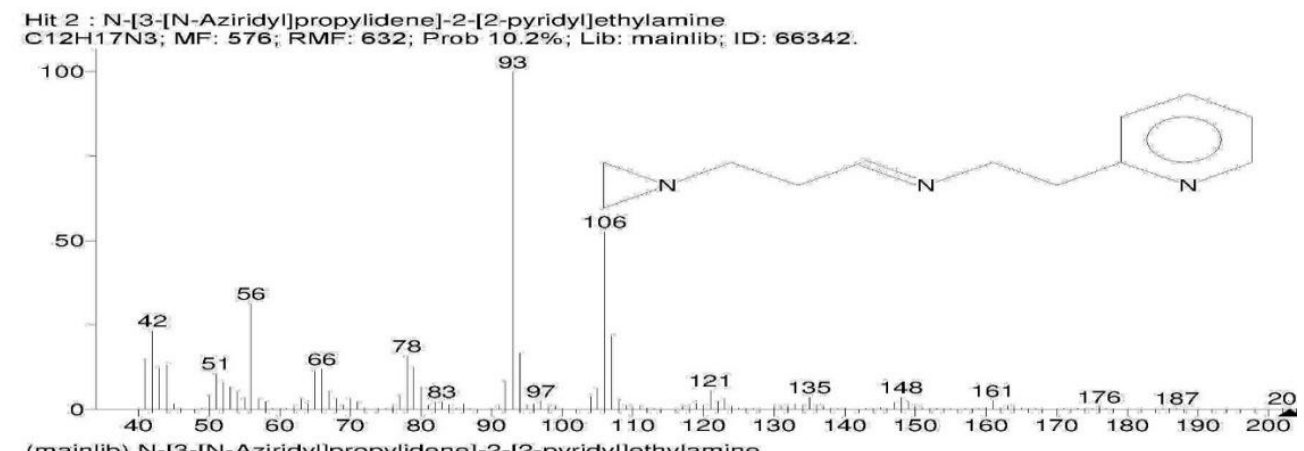
(mainlib) N-[3-[N-Aziridyl]propylidene]-2-[2-pyridyl]ethylamine

Hit 1 : Actinomycin $\mathrm{G2}$
C63H8sN12016; MF:

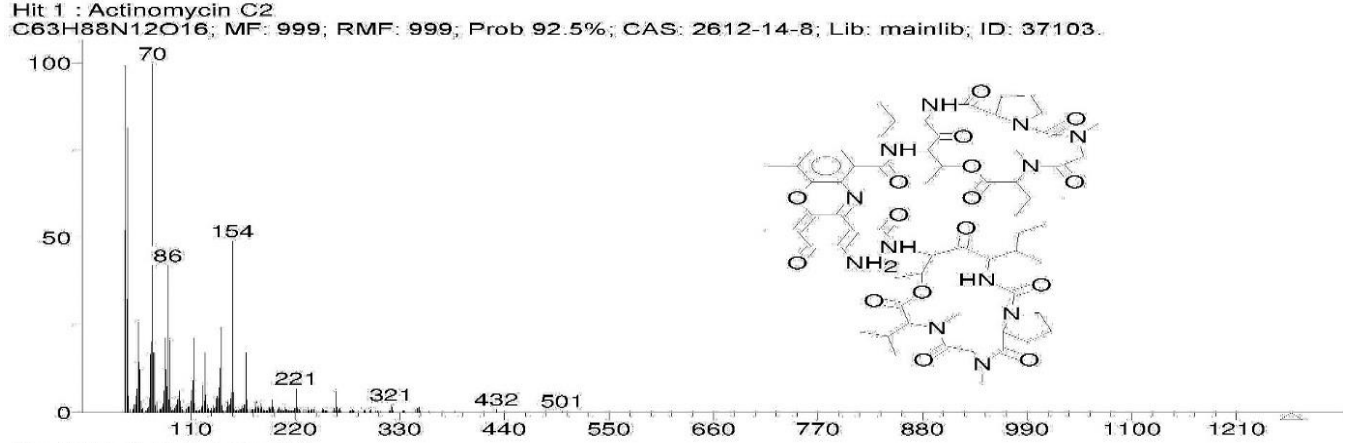

(mainlib) Actinomycin C2

Hit $1:$ 1-Methyl-4-[nitromethyl]-4-piperidinol

C7H14N2O3; MF: 592; RMF: 654; Prob 25.2\%; CAS: 116250-49-8; Lib: mainlib; ID: 15256

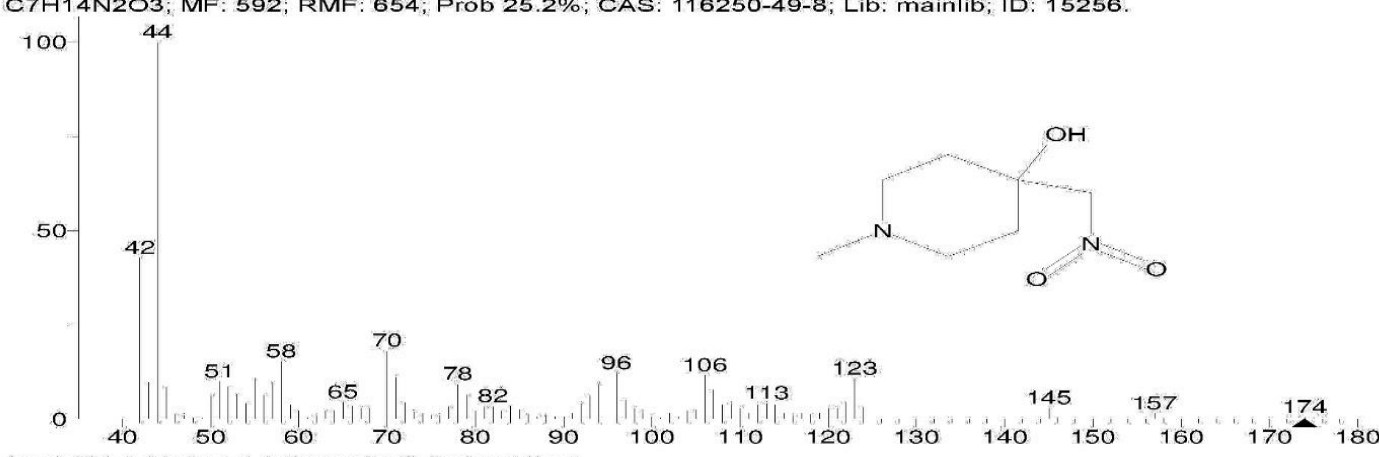

(mainlib) 1-Methyl-4-[nitromethyl]-4-piperidinol

Hit 1 : N-[2-[I2-Pyridylmethy]]amino]ethyl]aziridine
C10H15N3; MF: 592; RMF: 653; Prob 17.8\%; Lib: mainlib; ID: 66262.

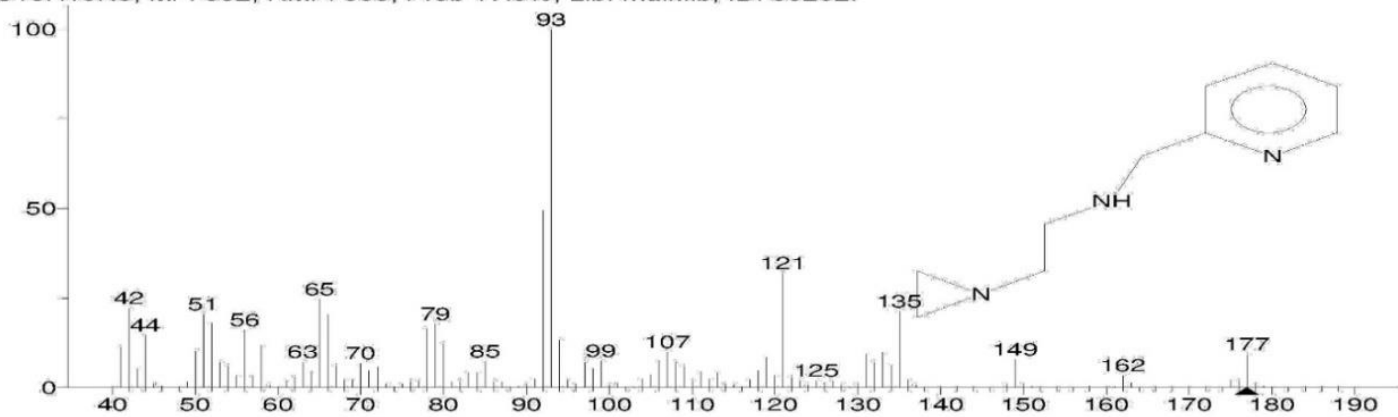

(mainlib) N-[2-[[2-Pyridylmethyl]amino]ethyl]aziridine

Hit 2 : Mannosamine

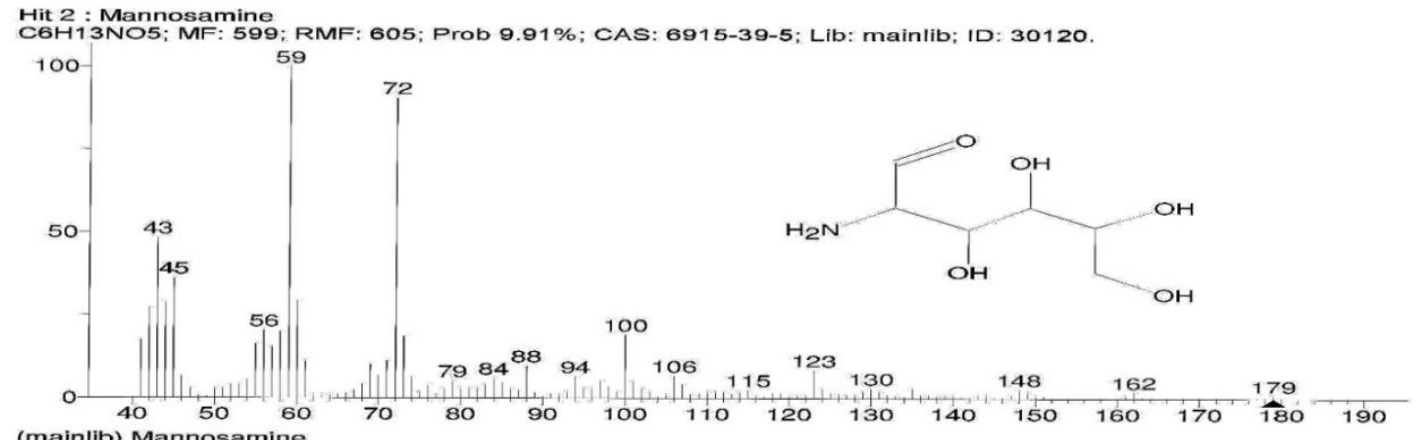

(mainlib) Mannosamine 
Chemical Constituents of Methanol Fruit Extract of Xylopia aethiopica by GC-MS and FT-IR Spectroscopy

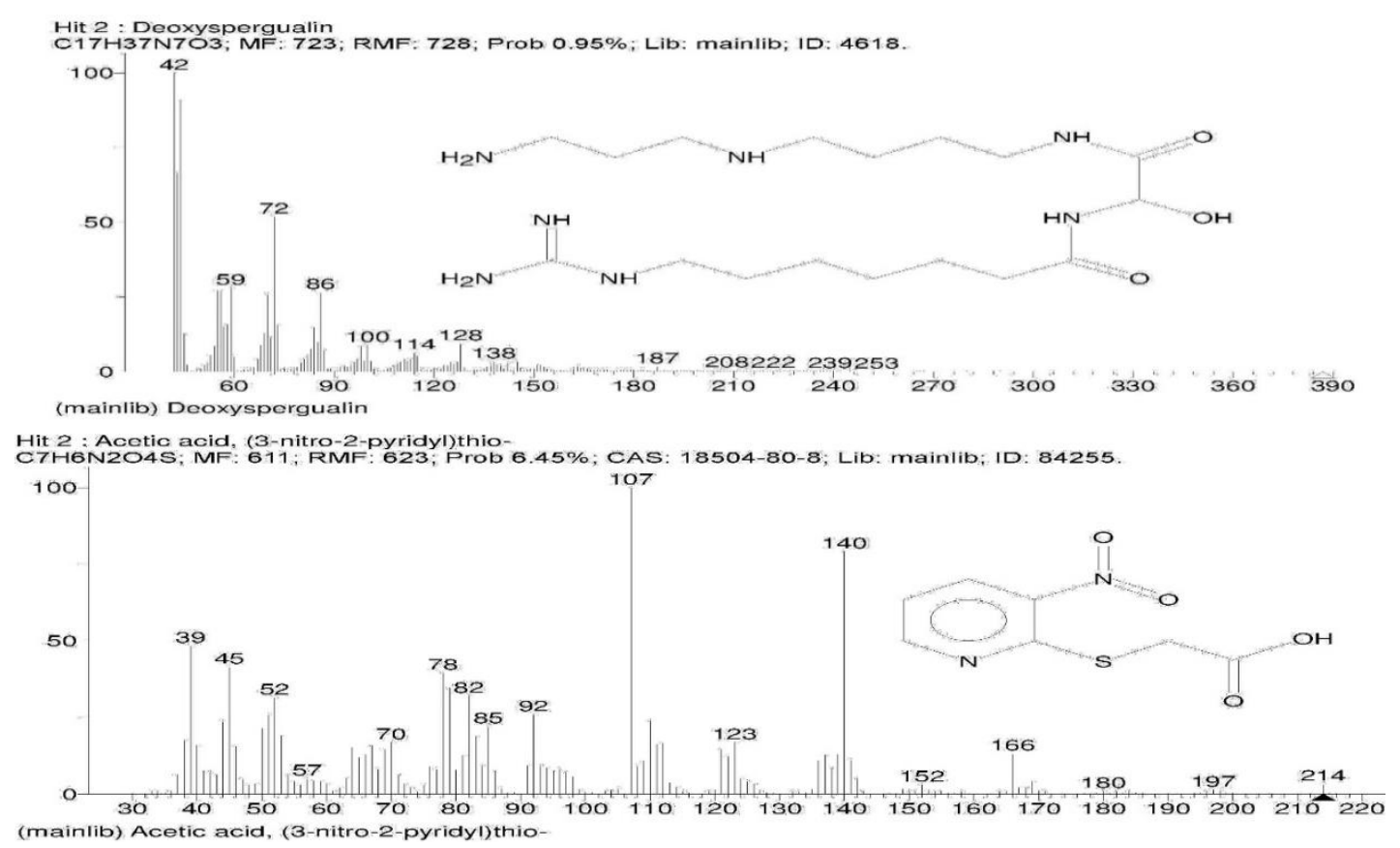

Figure2. The Mass spectra of methanol fruit extract of Xylopia aethiopica

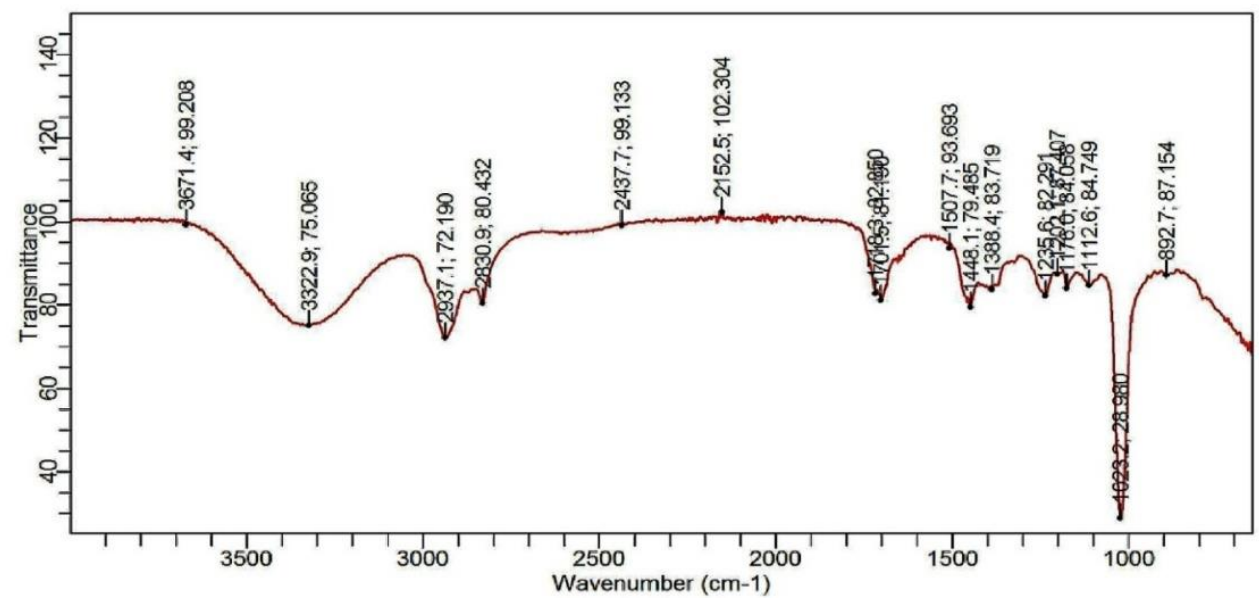

Figure3. FTIR Spectrum of methanol fruit extract of Xylopia aethiopica

Table1. FTIR Analysis of Xylopia aethiopica

\begin{tabular}{|l|l|l|}
\hline $\begin{array}{l}\text { Absorption frequency } \\
\left(\mathrm{CM}^{-1}\right)\end{array}$ & Functional Group & Stretching/bending Vibration \\
\hline 3671.5 & Hydroxyl & O-H \\
3322.9 & Aliphatic amine & N-H \\
\hline 2937.1 & Alkanes & C-H \\
\hline 2830.9 & Alkanes & C-H \\
\hline 1701.5 & Carbonyl & C=O \\
1507.7 & Alkene & C=C bending \\
1448.1 & Hydroxyl & O-H Bending \\
1176.0 & Alcohol/Esther & C-O bending \\
\hline
\end{tabular}

\section{CONCLuSiON}

At this moment, there is a growing demand globally in herbal medicines associated with improved laboratory investigation into the pharmacological properties of the bioactivities from natural source 
and their ability to manage an assortment of diseases. Exploration of herbal medicines had created an avenue for several conventional and alternative therapies. The present study identified 26 bioactive compounds in the methanol extract of Xylopia aethiopica fruits using gas chromatography-mass spectrometry (GC-MS) and Fourier Transform Infra-red spectroscopy revealed the functional groups. This plant has many bioactive compounds that possess antioxidant, anti-inflammatory, anti-microbial and anticancer properties. This showed that the plant extract should be of great pharmaceutical interest. Haven identified many bioactive compounds in methanol extract of Xylopia aethiopica fruits in the present study, and it is recommended that the active ingredients are isolated and subjected to further tests to compare their usefulness in the prevention and treatment of various ailments.

\section{REFERENCES}

[1] Etoundi C.B., Kuaté D., Ngondi J.L., Oben J.(2010) Antiamylase, anti-lipase and antioxidant effects of aqueous extracts of some Cameroonian spices. Journal of Natural Products,3:165-171

[2] Grover, J.K., Yadav, S. and V. Vats. (2002). Medicinal plants of India with anti-diabetic potential. Journal of Ethnopharmacology, 81: 81-100.

[3] Lai, P.K. and J. Roy. (2004) Antimicrobial and chemopreventive properties of herbs and spices. Current Medicinal Chemistry, 11(11): 1451-1460

[4] Tan, A.C., Konczak, I., Sze, D.M. and I. Ramzan. (2010)Towards the discovery of novel phytochemicals for disease prevention from native Australian plants: an ethnobotanical approach. Asian Pacific Journal Clinical Nutrition, 19(3): 330-334.

[5] Tapsell, L.C., Hemphill, I., and Cobiac, L., Patch, C.S., Sullivan, D.R., Fenech, M., Roodenrys, S., Keogh, J.B., Clifton, P.M., Williams, P.G., Fazio, V.A. and K.E. Inge. (2006). Health benefits of herbs and spices: the past, the present, the future. Medicinal Journal of Australia, 185(4): S4-24

[6] Gurib-Fakim, A. (2006). Medicinal plants: Traditions of yesterday drugs of tomorrow. Molecular Aspects of Medicine, 27(1): 1-93

[7] Ogbonnia, SO, Mbaka, GO, Anyika, EN, Emordi, JE, and Nwakakwa, N. (2011). An evaluation of acute and subchronic toxicities of a Nigerian polyherbal tea remedy. Pak J Nutr10:1022-8.

[8] Chang, IM. (1987). Toxicity of herbal drugs, International Forum on Research and Development for Procedures involving Risk Assessment of Toxic Chemicals. In Korean Soc. Toxicol(Chang IM ,ParkCWeds). pp: 243-257.

[9] Rickert, K, Martinez,RR,,and Martinez, TT (1999). Pharmacist knowledge of common herbal preparations. Proc West Pharmacol Soc.42:1-2.

[10] Alam, MB., Hossain, MS,. Chowdhury, NS, Mazumder, MEH. andHaque, ME. (2011). In vitro and in vivo antioxidant and toxicity evaluation of different fractions of Oxalis corniculatalinn. $J$ PharmacolToxicol; 6:337-48.

[11] Orwa, C., Mutua, A. , Kindt, R. , Jamnadass, R. and Simons, A. (2009). AgroforestreeDatabase:a tree reference and selection guide. Version 4.0 (http://www.worldagroforestry.org/af/treedb/)

[12] Funmilayo Gladys Famuyiwa, Marcus Durojaye Ayoola, Samson Oluwaseyi Famuyiwa, Adetunji Joseph Aladesanmi ((2018).Hyperglycaemia Lowering Effect of Kaurane Diterpenoids from the Fruits of Xylopia aethiopica(A. Dunal) Rich International Journal of Medicinal Plants and Natural ProductsVolume 4, Issue 3, PP 11-19

[13] Soladoye, M.O., Chukwuma, E.C. and F.P. Owa. 2012. An 'Avalanche' of plant species for the traditional cure of diabetes mellitus in South-Western Nigeria. Journal of Natural Product and Plant Resources, 2:60-72.

[14] Burkill, H. M (1985). "Entry for Xylopia aethiopica Dunal A. Rich. : family Annonceae". The useful plants of west tropical Africa, Vol 1 (JSTOR). Retrieved 12 March. 2020.

[15] Dalziel, J.M. (1973). The useful plants of Tropical West Africa. Crown overseas Agents colonies London, pp: 461.

[16] Tairu, A.O.; Hofmann, T.; and Schieberle, P. (1999). Characterization of the key aroma compounds in dried fruits of the West African Peppertree Xylopia aethiopica (Dunal) A. Rich (Annonaceae) using aroma extract dilution analysis. J. Agric. Food Chem. 47, 3285-3287.

[17] Choudhury, M. H., Terence, M. H., and Peter, G. W. (1982). Kolavane and kauranediterpenes from the stem bark of Xylopia aethiopica .Phytochemistry, 21, 1365.

[18] Ayedoun, AM, Adeoti, BS, and Sossou, PV. (1996). Influence of fruit conservation methods on the essential oil composition of Xylopia aethiopica (Dunal) A. Richard from Benin. Flav. Fragr. J. 11: 245 
[19] Watt, J. M. and Breyer-Brandwijk, M. G.(1962). The Medicinal and Poisonous Plants of Southern and Eastern Africa. 2nd Edition, E. \& S. Livingstone Ltd., Edinburgh and London; p. 830.

[20] Ahamefula A.A, Godwin .I. O, A I. Obike, Chisom .S.E, Okoronkwo J. C, John Bull O. E(2018).GC-MS Analysis of Bioactive Compounds from Whole Plant Chloroform Extract of Ageratum conyzoides. International Journal of Medicinal Plants and Natural Products.Vol 4, Issue 2,13-24

[21] Lewis, W.H., Elvin-Lewis M.P.F.(2003) Medical Botany: Plants Affecting Human Health, 2nd Ed., Wiley. New Jersey.

[22] Duthie, G.G., Gardner, P.T., Kyle, J.A.(2003) Plant polyphenols: are they the new magic bullet? Proc. Nutr. Soc.62: 599-603

[23] Sawa, T., Nako, M., Akaike, T., Ono, K., Maeda, H.(1999) Alkylperoxyl radical scavenging activity of various flavonoids and other phenolics compounds: Implimantations for the antitumar promoter effect of vegetables. Journal of Agriculture and Food Chemistry, 47: 397- 492

[24] Fleischer TC.(2003) Xylopia aethiopica A Rich.: A chemical and biological perspective. Journal University Science Technology. 23:24-31.

[25] Iwu M. (1993) Handbook of African medicinal plants. FL.CRC Press, Roca Raton, Ronald Hites, (1997)A. Handbook of Instrumental Techniques for Analytical Chemistry (Settle, F.A., ed.), Upper Saddle River, NJ, pp. 609-626

Citation: Ahamefula. A. Ahuchaogu, et.al, "Chemical Constituents of Methanol Fruit Extract of Xylopia aethiopica by GC-MS and FT-IR Spectroscopy”, ARC Journal of Pharmaceutical Sciences , 6(1), pp. 14-24. DOI: http://dx.doi.org/10.20431/2455-1538.0601003

Copyright: () 2020 Authors, This is an open-access article distributed under the terms of the Creative Commons Attribution License, which permits unrestricted use, distribution, and reproduction in any medium, provided the original author and source are credited. 